\title{
Association of the vascular endothelial growth factor -2578C/A polymorphism with cancer risk: A meta-analysis update
}

\author{
QUANCHI CHEN", ZIFEI ZHOU*, LIANGCHENG SHAN, YINGQI HUA, \\ HUI ZENG, PENGCHENG LIU and ZHENGDONG CAI
}

\author{
Department of Orthopedics, Shanghai Tenth People's Hospital, Tongji University, Shanghai 200072, P.R. China
}

Received January 10, 2014; Accepted June 25, 2014

DOI: $10.3892 /$ br.2014.317

\begin{abstract}
The vascular endothelial growth factor (VEGF) -2578C/A polymorphism has been previously reported to be associated with cancer risk; however, the results have been controversial. Therefore, the aim of the present study was to explore the association between the VEGF -2578C/A polymorphism with the cancer risk. A total of 37 case-control studies were identified. The pooled analysis showed that there was no association between VEGF -2578C/A and the risk of cancer, and the odds ratios (ORs) [with the corresponding 95\% confidence intervals (95\% CIs)] were 0.97 (0.91-1.04) for C vs. A, 0.94 (0.86-1.02) for CC vs. AA, 0.92 (0.80-1.06) for CA vs. AA, 0.96 (0.89-1.03) for CC/CA vs. AA and 0.97 (0.88-1.08) for CC vs. CA/AA. Subgroup analyses according to ethnicity, source of control and type of cancer showed that the VEGF -2578C/A polymorphism is associated with colorectal and lung cancers. Additionally, the polymorphism may decrease the risk of cancer in the Asian population. This VEGF polymorphism was not associated with a risk of cancer for the Caucasian [0.92 (0.76-1.11) for CC vs. AA] and African populations [1.31 (0.67-2.58) for CC vs. AA], and it was not associated with bladder [1.06 (0.74-1.53) for CC/AA] and breast cancers [1.01 (0.90-1.15) for CC/AA]. Therefore, the present meta-analysis indicates that VEGF -2578C/A may only be associated with the risk of colorectal cancer, lung cancer and the Asian population. More studies with larger sample sizes are required to provide more conclusive evidence.
\end{abstract}

\section{Introduction}

Cancer has become one of the leading causes of mortality worldwide due to genetic and environmental factors. However, the exact

Correspondence to: Professor Zhengdong Cai, Department of Orthopedics, Shanghai Tenth People's Hospital, Tongji University, 301 Yanchang Road, Shanghai 200072, P.R. China

E-mail:czd856@vip.Sohu.com

*Contributed equally

Key words: vascular endothelial growth factor, polymorphism, cancer susceptibility, meta-analysis mechanism of carcinogenesis remains largely unknown (1). With research developing, it is becoming clear that the characteristics of cancer, which are founded on genome instability, include maintaining proliferative signaling, enabling replicative immortality, inducing angiogenesis, invasion and metastasis, reprogramming the energy metabolism, evading growth suppressors, resisting cell death and evading immune destruction (2). Recently, it has become evident that genetic variation plays a significant role in the development and progression of cancer. More studies based on gene polymorphisms have proved that the polymorphisms may contribute to the cancer risk (3).

Vascular endothelial growth factor (VEGF) plays a key role in a number of pathological processes, including angiogenesis, tumor growth and metastasis. VEGF plays an important role in tumor angiogenesis through promoting endothelial cell growth and migration (4). The human VEGF gene is located on chromosome 6 p21.3 and includes a 14-kb coding region with eight exons and seven introns (5). Certain polymorphisms have been identified in the VEGF gene. In order to evaluate the association between the VEGF polymorphism with the various types of cancer risk, numerous molecular epidemiological studies have been performed in different populations recently (6). However, there were no clear conclusions due to inconsistent statistical results. Some of these conclusions may ascribe to the possible small influence of the gene polymorphism on the cancer risk and others may be caused by the relatively small samples in these published studies. Specific meta-analyses analyzed the association for only one type of cancer, including colorectal, lung or bladder cancer. Therefore, a relatively comprehensive meta-analysis was performed, including the most recent and relevant studies to provide more accurate statistical evidence for the association between the VEGF polymorphism and risk of the types of cancer that have been studied (7-40). Meta-analysis can alleviate the problems caused by small samples and deficient statistical genetic studies of multiple traits. Therefore, it can provide more reliable results than a single case-control study. The aim of the present study was to utilize the meta-analysis to summarize the relevant studies regarding the VEGf $-2578 \mathrm{C} / \mathrm{A}$ polymorphism and the risk of cancer.

\section{Materials and methods}

Identification and eligibility of relevant studies. The relevant studies that were published by August 23, 2013 were identified 
using the Embase, PubMed, Web of Science and Chinese National Knowledge Infrastructure databases. The following terms were used in the search: 'Genetic polymorphism', 'polymorphism' or 'genetic variants'; 'VEGF' or 'vascular endothelial growth factor'; and 'cancer' or 'carcinoma'. The case-control and cohort studies that explored the association between the VEGF polymorphism and cancer risk with genotyping data were included. All the eligible studies were reviewed and only the published studies were included in the meta-analysis. For studies in which the data partly overlapped, only the most recent or complete studies were included. When the same sample was applied to several different studies, the most integrated data was selected following careful examination.

Inclusion and exclusion criteria. The studies that were included in the meta-analysis met the following criteria: i) Case-control studies focused on the associations between the VEGF -2578C/A polymorphism and cancer risk; ii) all the patients were diagnosed by pathological or histological examinations; iii) the frequencies of the genotypes in cancer cases and controls could be extracted; and iv) published in English or Chinese. The excluded studies were: i) Not case-control studies; ii) published in a language other than English or Chinese; and iii) were letters, reviews, meta-analyses or editorial studies.

Data extraction. The data were independently extracted from all the eligible studies by two investigators according to the aforementioned inclusion criteria. From each study, the following information was extracted: First author's name, year of publication, country, ethnicity, type of cancer, DNA sample, source of controls, study design, methods and total number of cases and controls. Ethnicity was categorized as the 'Caucasian,' 'African,' (including African-Americans) and 'Asian' populations. One study did not state the included ethnic groups according to phenotype, and therefore, the sample was known as 'mixed' (29). However, each control was individually matched to a case with regards to birth date ( \pm 6 months), date of blood collection ( \pm 6 months) and ethnicity (Caucasian, African-American, Hispanic, Asian and other/unknown). Furthermore, the studies investigating more than one type of cancer were considered as individual data sets only in the subgroup analyses by the type of cancer. There was no definition as to the minimum number of patients that were included in the present meta-analysis. The studies that reported different ethnic groups and countries or locations, were considered as separate study samples for each aforementioned category.

Statistical analysis. The statistical analyses were performed using Stata software (version 9.0; StataCorp, College Station, TX, USA). Heterogeneity among the various studies was assessed by the Q-statistic and quantified by calculating the $\mathrm{I}^{2}$ value. According to the $\mathrm{Q}$-statistic, heterogeneity was significant when $\mathrm{P}<0.10$. Among the studies, the $\mathrm{I}^{2}$ value demonstrated the percentage of variation associated with heterogeneity, instead of chance. No heterogeneity was observed when $\mathrm{I}^{2}=0 \%$, and $0-25 \%$ accounted for low, $25-50 \%$ for moderate and $50-75 \%$ for high heterogeneity. Consistent with published recommendations (29) for the quality assessment in genetic

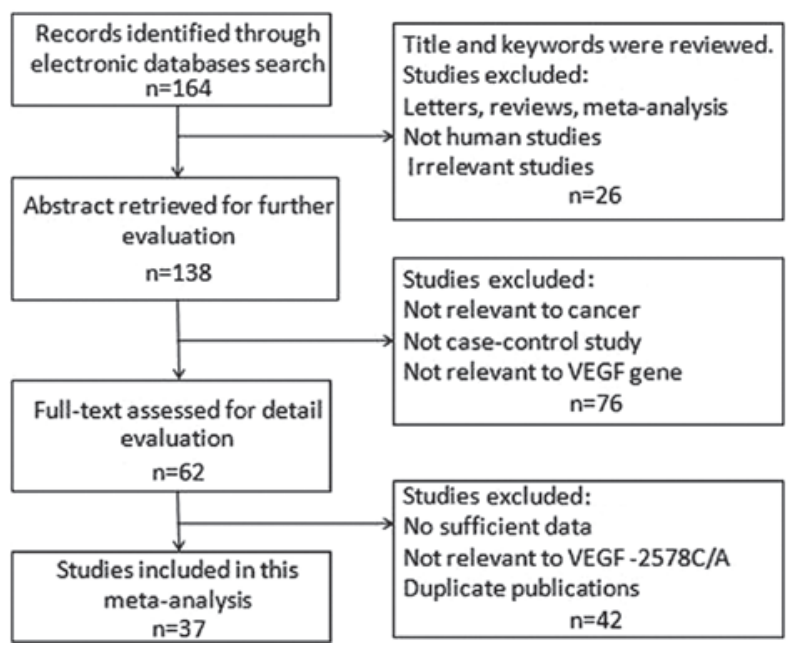

Figure 1. Flowchart for the selection of the primary studies in the present meta-analysis. VEGF, vascular endothelial growth factor.

association meta-analyses, three genetic models were selected: Allele (C vs. A), for homozygote (CC vs. AA) and heterozygote comparisons (CA vs. AA); dominant (CC+CA vs. AA); and recessive models (CC vs. $\mathrm{CA}+\mathrm{AA})$, to prevent the use of the wrong genetic model. For each study, the odds ratio (OR), together with the corresponding $95 \%$ confidence interval (95\% CI), was calculated to assess the association between the VEGF polymorphism and the risk of cancer. Meta-analysis was performed for the polymorphisms that had been investigated in at least two studies. The overall estimate of risk (OR) was calculated by a fixed-effects (Mantel-Haenszel) or a random-effects model (DerSimonian-Laird) according to the presence $\left(\mathrm{P}<0.10\right.$ or $\left.\mathrm{I}^{2}>50 \%\right)$ or absence $\left(\mathrm{P}>0.10\right.$ or $\left.\mathrm{I}^{2}<50 \%\right)$ of heterogeneity, respectively. In addition to the comparison among all the groups, subgroup analysis was performed in correlation with the type of cancer and ethnicity. The significant differences in genotype and allelic frequency between the two groups were determined using the $\chi^{2}$ test. In order to exclude the allele frequencies in the controls, deviating greatly from the Hardy-Weinberg equilibrium, the $\chi^{2}$ test (minimum Pearson $\chi^{2}$ estimate) was performed in the sensitivity analysis and deviation was considered when $\mathrm{P}<0.01$. All the statistical tests were two-sided and $\mathrm{P}<0.05$ was considered to indicate a statistically significant difference.

\section{Results}

Characteristics of studies. According to the inclusion and exclusion criteria, 37 case-control studies were included that ranged between 2002 and 2013 (Fig. 1). Among these studies, 17 were studies of the Caucasian population and 18 were of the Asian population. All the patients were diagnosed histologically or pathologically. Blood samples were used for genotyping in 30 studies and tissue samples were used in eight studies. A total of 20 studies used hospital-based controls, whereas 15 studies used population-based controls. The polymerase chain reaction-restriction fragment length polymorphism assay was used for genotyping in 13 studies, whereas the TaqMan assay was used in 11 studies. The details of the included studies are summarized in Table I. 
Table I. Characteristics of the primary studies in the meta-analysis.

\begin{tabular}{|c|c|c|c|c|c|c|c|c|c|c|c|}
\hline First author & Year & Country & Ethnicity & Cancer type & $\begin{array}{c}\text { DNA } \\
\text { sample }\end{array}$ & $\begin{array}{c}\text { Source of } \\
\text { control }\end{array}$ & $\begin{array}{l}\text { Study } \\
\text { design }\end{array}$ & Methods & Case, $n$ & Control, $\mathrm{n}$ & (Refs.) \\
\hline Howell & 2002 & UK & Caucasian & CMM & Tissue & Unknown & Case-cont & Unknown & 134 & 266 & (15) \\
\hline Kim & 2005 & Korea & Asian & Bladder & Blood & HB & Case-cont & TaqMan & 153 & 153 & (41) \\
\hline \multirow[t]{3}{*}{ Jin } & 2005 & Poland & Caucasian & Breast & Tissue & $\mathrm{PB}$ & Case-cont & PCR-RFLP & 411 & 423 & (21) \\
\hline & 2005 & Germany & Caucasian & Breast & Tissue & PB & Case-cont & PCR-RFLP & 153 & 162 & \\
\hline & 2005 & Sweden & Caucasian & Breast & Tissue & PB & Case-cont & PCR-RFLP & 939 & 940 & \\
\hline Jacobs & 2006 & America & Mixed & Breast & Blood & $\mathrm{PB}$ & Case-cont & TaqMan & 498 & 495 & (18) \\
\hline Hofmann & 2008 & Austria & Caucasian & Colorectal & Blood & $\mathrm{PB}$ & Case-cont & TaqMan & 433 & 427 & (14) \\
\hline Nikiteas & 2007 & Greece & Caucasian & Gastric & Blood & $\mathrm{HB}$ & Case-cont & PCR & 100 & 100 & (32) \\
\hline Hsiao & 2007 & Taiwan & Asian & Thyroid & Blood & $\mathrm{HB}$ & Case-cont & TaqMan & 297 & 249 & (16) \\
\hline Park & 2007 & Korea & Asian & Colorectal & Blood & $\mathrm{HB}$ & Case-cont & PCR & 203 & 246 & (33) \\
\hline Pharoah & 2005 & UK & Caucasian & Breast & Unknown & PB & Case-cont & TaqMan & 2015 & 2139 & $(34)$ \\
\hline Nasr & 2008 & Tunisia & African & $\begin{array}{l}\text { Nasopharyngeal } \\
\text { carcinoma }\end{array}$ & Blood & HB & Case-cont & PCR-RFLP & 163 & 169 & $(31)$ \\
\hline Diao & 2009 & China & Asian & $\begin{array}{l}\text { Non-Hodgkin's } \\
\text { lymphoma }\end{array}$ & Blood & $\mathrm{HB}$ & Case-cont & PCR-RFLP & 431 & 172 & (11) \\
\hline $\mathrm{Ke}$ & 2008 & China & Asian & Gastric & Blood & $\mathrm{PB}$ & Case-cont & PCR-RFLP & 540 & 561 & (23) \\
\hline Dassoulas & 2009 & Greece & Caucasian & Colorectal & Tissue & $\mathrm{HB}$ & Case-cont & TaqMan & 312 & 362 & (9) \\
\hline Maltese & 2009 & Italy & Caucasian & Colorectal & Blood & PB & Case-cont & PCR & 302 & 115 & (28) \\
\hline Liang & 2009 & China & Asian & Lung & Blood & HB & Case-cont & PCR-RFLP & 171 & 172 & (27) \\
\hline $\mathrm{Wu}$ & 2009 & China & Asian & $\begin{array}{l}\text { Hepatocellular } \\
\text { carcinoma }\end{array}$ & Blood & $\mathrm{HB}$ & Case-cont & TaqMan & 92 & 99 & (39) \\
\hline Zhang & 2011 & China & Asian & Colorectal & Blood & $\mathrm{HB}$ & Case-cont & PCR-RFLP & 110 & 110 & (40) \\
\hline $\mathrm{Li}$ & 2010 & China & Asian & Ovarian & Blood & $\mathrm{PB}$ & Case-cont & PCR-RFLP & 303 & 303 & (26) \\
\hline Kämmerer & 2013 & Germany & Caucasian & $\begin{array}{l}\text { Oral squamous } \\
\text { cell carcinoma }\end{array}$ & Blood & $\mathrm{HB}$ & Case-cont & RT-PCR & 80 & 40 & (22) \\
\hline VanCleave & 2010 & America & African & Prostate & Blood & $\mathrm{HB}$ & Case-cont & TaqMan & 190 & 635 & (37) \\
\hline Wang & 2011 & China & Asian & $\begin{array}{l}\text { Nasopharyngeal } \\
\text { carcinoma }\end{array}$ & Blood & $\mathrm{HB}$ & Case-cont & PCR-RFLP & 156 & 161 & (38) \\
\hline Galimberti & 2010 & Italy & Caucasian & $\begin{array}{l}\text { Mantle cell } \\
\text { lymphoma }\end{array}$ & Blood & PB & Case-cont & RT-PCR & 32 & 58 & (12) \\
\hline Kim & 2010 & Korea & Asian & Cervical & Blood & $\mathrm{HB}$ & Case-cont & PCR & 199 & 211 & (24) \\
\hline Ajaz & 2011 & Pakistan & Asian & $\begin{array}{l}\text { Renal cell } \\
\text { carcinoma }\end{array}$ & Blood & PB & Case-cont & TaqMan & 143 & 106 & (7) \\
\hline Jang & 2013 & South Korea & Asian & Colorectal & Blood & HB & Case-cont & PCR-RFLP & 390 & 492 & (20) \\
\hline Supic & 2012 & Serbia & Caucasian & $\begin{array}{l}\text { Oral squamous } \\
\text { cell carcinoma }\end{array}$ & Blood & $\mathrm{PB}$ & Case-cont & TaqMan & 114 & 126 & (36) \\
\hline $\begin{array}{l}\text { Henríquez- } \\
\text { Hernández }\end{array}$ & 2012 & Spain & Caucasian & Bladder & Blood & $\mathrm{HB}$ & Case-cont & PCR-RFLP & 59 & 43 & (13) \\
\hline Sáenz-López & 2013 & Spain & Caucasian & $\begin{array}{l}\text { Renal cell } \\
\text { carcinoma }\end{array}$ & Tissue & $\mathrm{HB}$ & Case-cont & RT-PCR & 216 & 272 & (35) \\
\hline $\mathrm{Li}$ & 2012 & China & Asian & Lung & Blood & $\mathrm{HB}$ & Case-cont & PCR-RFLP & 150 & 150 & (25) \\
\hline Jaiswal & 2013 & India & Asian & Bladder & Blood & HB & Case-cont & PCR-RFLP & 250 & 200 & (19) \\
\hline Moon & 2013 & India & Asian & Colorectal & Blood & PB & Case-cont & PCR & 390 & 492 & (20) \\
\hline Ianni & 2013 & Italy & Caucasian & Prostate & Blood & $\mathrm{PB}+\mathrm{HB}$ & Case-cont & TaqMan & 224 & 156 & (17) \\
\hline Martinez-Fierro & 2013 & Mexico & Caucasian & Prostate & Tissue & Unknown & Case-cont & PCR-RFLP & 77 & 172 & (29) \\
\hline Mishra & 2013 & India & Asian & Bladder & Blood & HB & Case-cont & PCR & 195 & 300 & (30) \\
\hline Liang & 2009 & China & Asian & Lung & Blood & PB & Case-cont & PCR & 171 & 172 & (27) \\
\hline Deng & 2014 & China & Asian & Lung & Blood & PB & Case-cont & PCR & 65 & 110 & (10) \\
\hline Antonacopoulou & 2011 & Greece & Caucasian & Colorectal & Tissue & Unknown & Case-cont & PCR & 222 & 263 & (8) \\
\hline
\end{tabular}

CMM, cutaneous malignant melanoma; Case-cont, case-control; HB, hospital-based; PB, population-based; PCR-RFLP, polymerase chain reaction-restriction fragment length polymorphism; RT, reverse transcription.

Quantitative data synthesis. The summary of the meta-analysis of the associations between VEGF -2578C/A and cancer risk is shown in Table II. The random-effects model was used when the heterogeneity was evident under the genetic models ( $P>0.05)$, otherwise the fixed-effects models was used. When all the eligible studies were pooled, no significant association 


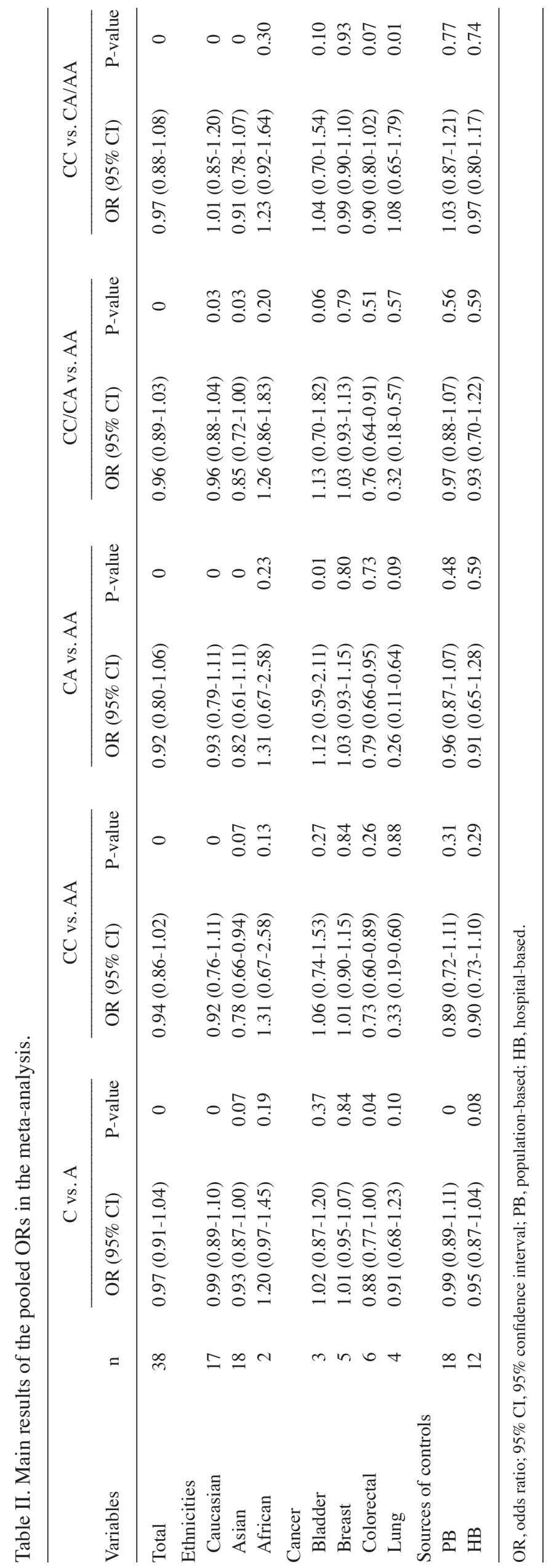




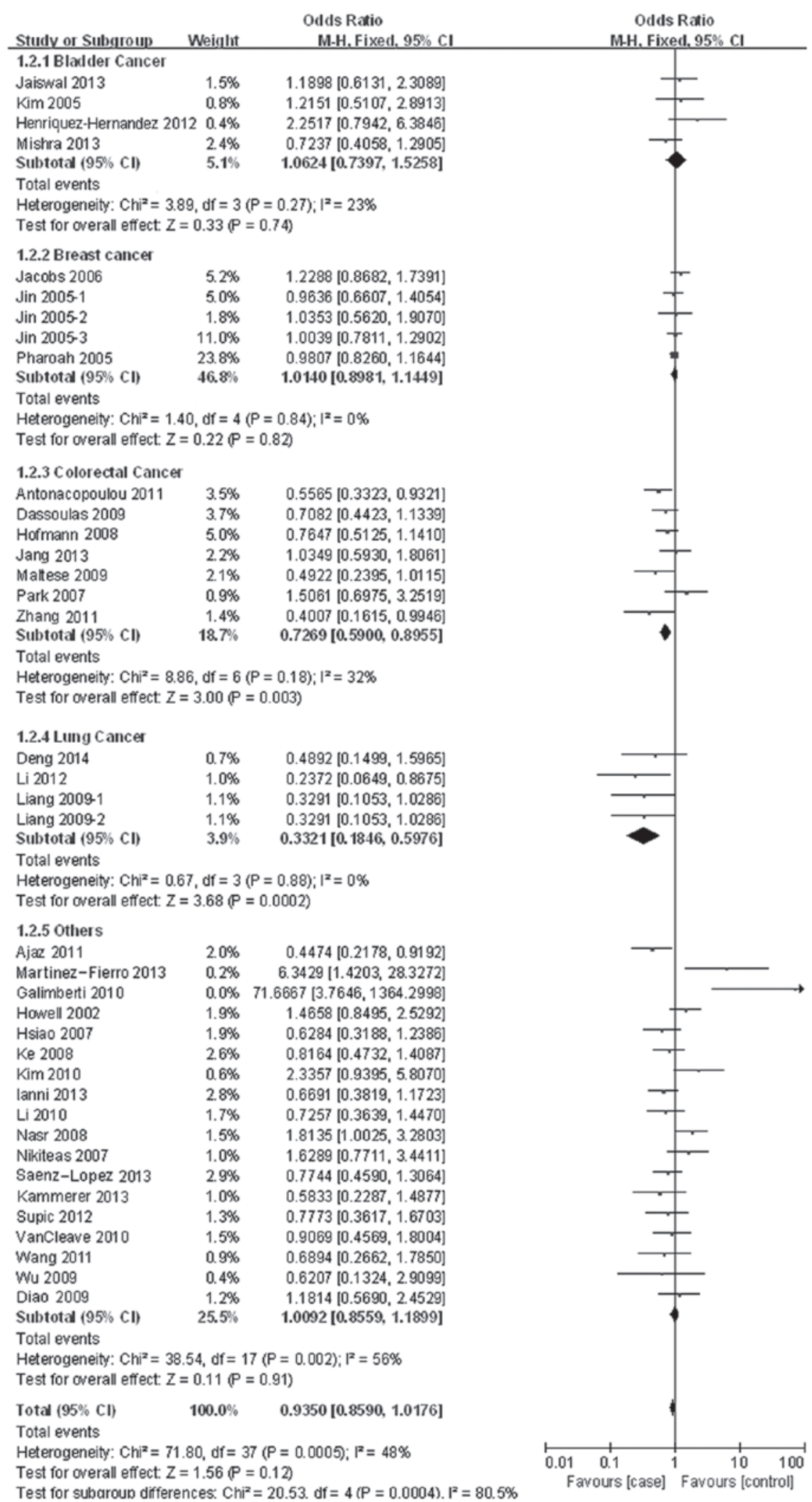

Figure 2. Forest plot of the cancer risk associated with vascular endothelial growth factor -2578C/A in various types of cancer [homozygote comparison (CC vs. AA)]. CI, confidence interval.

was observed between the VEGF -2578C/A polymorphism and the risk of cancer (CC vs. AA: OR, 0.4; 95\% CI, 0.86-1.02; $\mathrm{P}=0$ for heterogeneity) (Fig. 2) or recessive model (CC vs. CA/AA: OR, 0.97; 95\% CI, 0.88-1.08; $\mathrm{P}=0$ for heterogeneity).
In the stratified analysis by ethnicities, the VEGF -2578C/A polymorphism was associated with a significant decrease risk in the Asian population in the three tested models ( $\mathrm{C}$ vs. A: OR, 0.93; 95\% CI, 0.87-1.00; $\mathrm{P}=0.07$ for heterogeneity; 


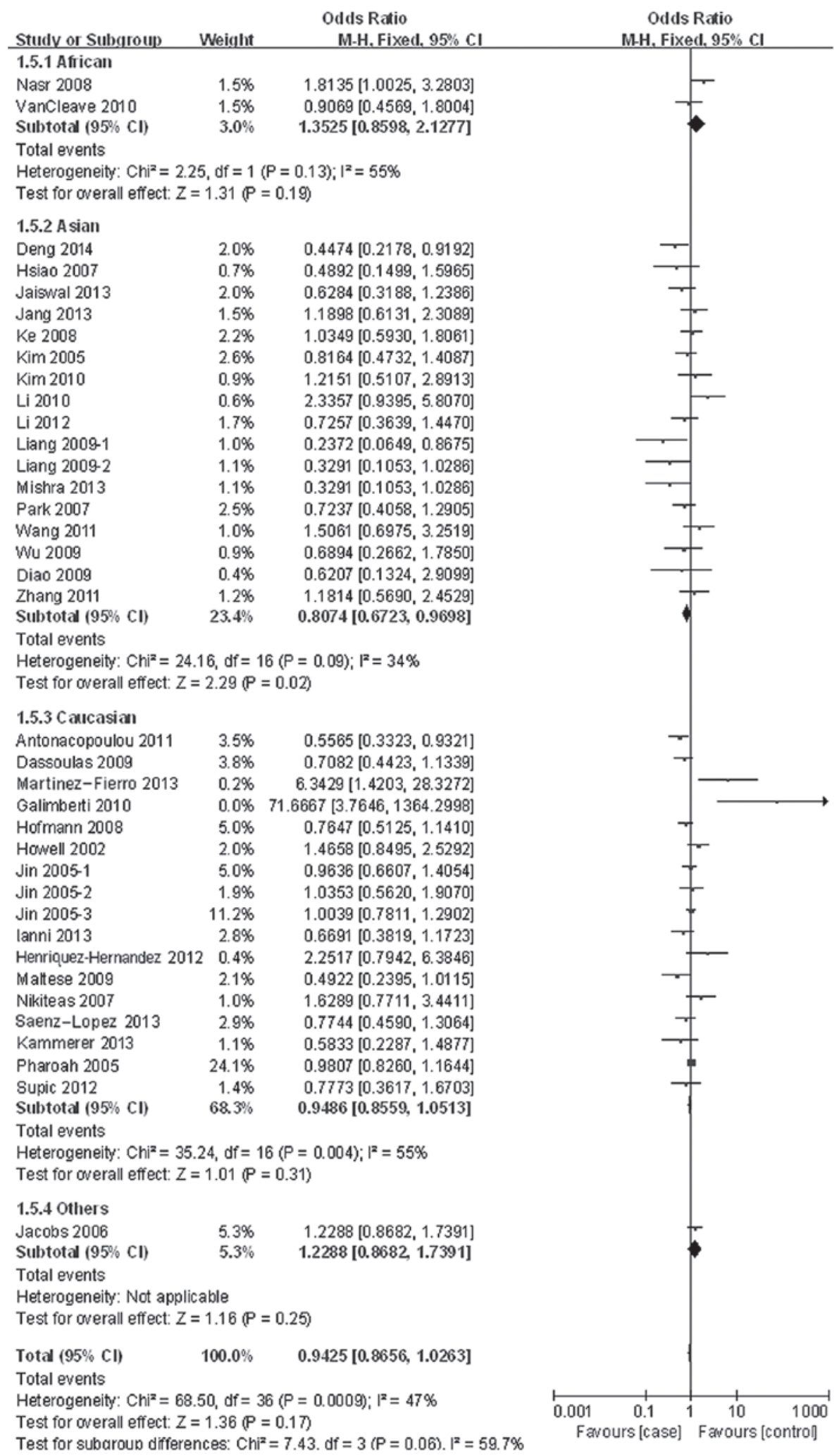

Figure 3. Forest plot of the cancer risk associated with vascular endothelial growth factor -2578C/A in various ethnicities [homozygote comparison (CC vs. AA)] CI, confidence interval.

CC vs. AA: OR, $0.78 ; 95 \%$ CI, 0.66-0.94; $\mathrm{P}=0.07$ for heterogeneity; and dominant model: OR, 0.85; 95\% CI, 0.72-1.00; $\mathrm{P}=0.03$ for heterogeneity) (Fig. 3), of colorectal cancer in four tested models (C vs. A: OR, 0.88; 95\% CI, 0.77-1.00; $\mathrm{P}=0.04$ for heterogeneity; $\mathrm{CC}$ vs. AA: OR, $0.73 ; 95 \% \mathrm{CI}, 0.60-0.89 ; \mathrm{P}=0.26$ for heterogeneity; CA vs. AA: OR, 0.79; 95\% CI, 0.66-0.95; $\mathrm{P}=0.73$ for heterogeneity; and dominant model: $\mathrm{OR}, 0.76$; 95\% CI, 0.64-0.91; P=0.51 for heterogeneity) (Fig. 2) and of lung cancer in three tested models (CC vs. AA: OR, 0.33; 95\% CI, 0.19-0.60; $\mathrm{P}=0.88$ for heterogeneity; $\mathrm{CA}$ vs. AA: 


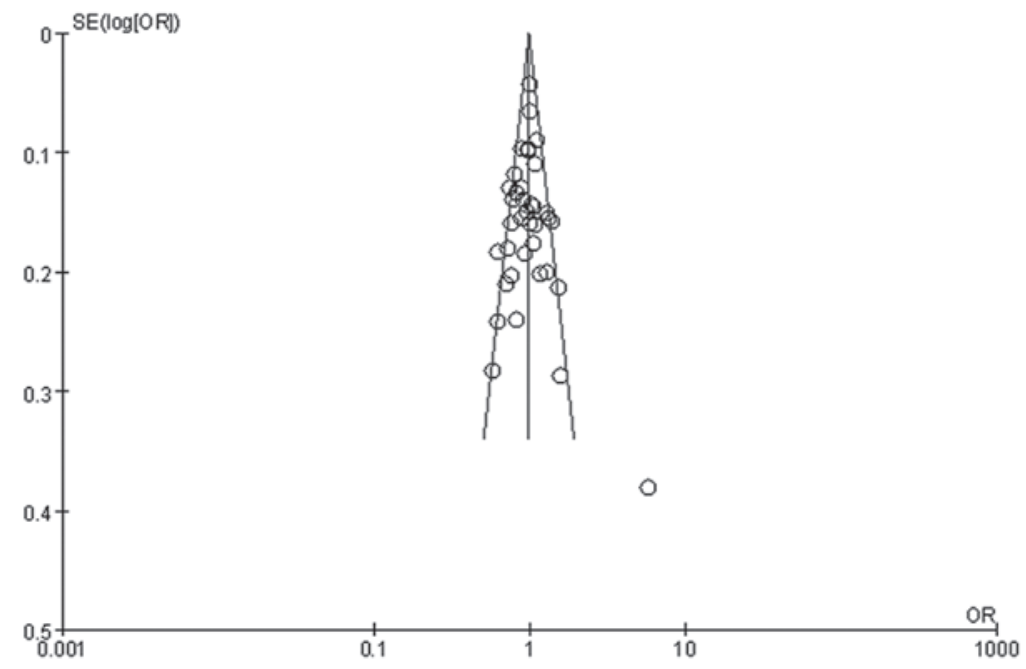

Figure 4. Begg's funnel plot for the publication bias test for vascular endothelial growth factor -2578C/A in the heterozygote comparison. SE, standard error; OR, odds ratio.

OR, 0.26; 95\% CI, 0.11-0.64; $\mathrm{P}=0.09$ for heterogeneity; and dominant model: OR, 0.32; $95 \%$ CI, $0.18-0.57$; $\mathrm{P}=0.57$ for heterogeneity) (Fig. 2). However, no associations were found with the other types of cancer (Table II).

Sensitivity analysis. Sensitivity analysis was performed to explore the influence of individual studies on the pooled results. No individual study was shown to affect the pooled OR significantly, as no substantial change was found.

Publication bias. Publication bias of the studies was assessed by Begg's funnel plot and Egger's test (Fig. 4). The arrangement of the data points did not reveal any evidence of clear asymmetry. Formal evaluation using Egger's regression asymmetry tests for the homozygote comparison did not show any evidence of publication bias $(\mathrm{t}=1.77 \mathrm{P}=0.086)$.

\section{Discussion}

Based on 37 cases-control studies, the present meta-analysis included 11,083 cases and 11,822 controls, and indicated that there was no association between the VEGF -2578C/A polymorphism and the risk of malignancy in the pooled analyses. Subgroup analyses with regards to the type of cancer showed specific positive associations. The VEGF -2578C/A polymorphism decreased the risk of colorectal and lung cancers under the codominant, dominant and recessive models. For future studies, the VEGF polymorphism could act as a predictive marker to develop a novel antiangiogenesis medicine. VEGF -2578C/A-targeted therapy could be applied to patients who want to receive an individualized treatment. However, in the stratified analysis by ethnicity and type of cancer, no evident co-association was observed. A different mechanism of carcinogenesis or various functions of the gene polymorphism may contribute to this phenomenon.

For the risk of colorectal and lung cancers, the present findings correspond to certain preceding studies that evaluated the influence of the VEGF -2578C/A polymorphism on the risk of these types of cancer (10). Significant heterogeneity did not exist in the present study, despite performing a careful search, establishing strict criteria, accurate data extraction and comprehensive analysis. Therefore, the subgroup analyses were performed to minimize the effects of heterogeneity in the following way: Ethnicity, type of cancer and sources of control.

Some of the limitations that existed in the present meta-analysis were inherent for all the previous meta-analysis that focused on single-nucleotide polymorphisms, and others were caused by artificial factors. Specific limitations in these studies should be carefully explained. First, ethnicity, multifarious types of cancer and various control sources gave rise to clear heterogeneity. Second, the number of certain cancer subgroups, including thyroid and ovarian cancers, was too small to investigate the potential existence of a correlation between the VEGF -2578C/A polymorphism and the corresponding cancer risk. Third, publication bias may have arisen due to the search languages that contain studies published only in English and Chinese. Fourth, the exclusion of unattained data generally contributed to a false estimation of the true effect. Regardless of the aforementioned limitations, advantages of the present meta-analysis were evidently facilitative to the final outcomes, which included a comprehensive searching method, strict analytical procedures and a significant conclusion that may contribute to individual therapy in the future.

In conclusion, the present study indicates that the VEGF $-2578 \mathrm{C} / \mathrm{A}$ polymorphism may have a particular association with certain types of cancer, including lung and colorectal cancers, and no evident association with breast cancer. More large scale samples, including various types of cancer, particularly in single studies, and different populations should be analyzed in a future meta-analysis to obtain a more conclusive understanding with regards to the function of the VEGF -2578C/A polymorphism in cancer development. More information, including medical history, exposure history, profession or even the climatic environment, should be obtained in future individual studies to assess the possible environmental-genome interaction. 


\section{References}

1. Babashah S and Soleimani M: The oncogenic and tumour suppressive roles of microRNAs in cancer and apoptosis. Eur $\mathrm{J}$ Cancer 47: 1127-1137, 2011

2. Hanahan D and Weinberg RA: Hallmarks of cancer: the next generation. Cell 144: 646-674, 2011.

3. Lacko M, Braakhuis BJ, Sturgis EM, et al: Genetic susceptibility to head and neck squamous cell carcinoma. Int J Radiat Oncol Biol Phys 89: 38-48, 2014.

4. Kaumaya PT and Foy KC: Peptide vaccines and targeting HER and VEGF proteins may offer a potentially new paradigm in cancer immunotherapy. Future Oncol 8: 961-987, 2012.

5. Vincenti V, Cassano C, Rocchi M and Persico G: Assignment of the vascular endothelial growth factor gene to human chromosome 6p21.3. Circulation 93: 1493-1495, 1996.

6. Yang Y, Zhang X, Song D and Wei J: Association between vascular endothelial growth factor gene polymorphisms and bladder cancer risk. Mol Clin Oncol 2: 501-505, 2014.

7. Ajaz S, Khaliq S, Abid A, et al: Association of a single-nucleotide polymorphism in the promoter region of the VEGF gene with the risk of renal cell carcinoma. Genet Test Mol Biomarkers 15 653-657, 2011.

8. Antonacopoulou AG, Kottorou AE, Dimitrakopoulos FI, et al: VEGF polymorphisms may be associated with susceptibility to colorectal cancer: a case-control study. Cancer Biomark 10: 213-217, 2011.

9. Dassoulas K, Gazouli M, Rizos S, et al: Common polymorphisms in the vascular endothelial growth factor gene and colorectal cancer development, prognosis, and survival. Mol Carcinog 48: 563-569, 2009.

10. Deng ZC, Cao C, Yu YM, Ma HY and Ye M: Vascular endothelial growth factor $-634 \mathrm{G} / \mathrm{C}$ and vascular endothelial growth factor -2578C/A polymorphisms and lung cancer risk: a case-control study and meta-analysis. Tumour Biol 35: 1805-1811, 2014.

11. Diao LP, Yu XM, Gao YH, et al: Association of VEGF genetic polymorphisms with the clinical characteristics of non-Hodgkin's lymphoma. J Cancer Res Clin Oncol 135: 1473-1481, 2009.

12. Galimberti S, Nagy B, Palumbo GA, et al: Vascular endothelial growth factor polymorphisms in mantle cell lymphoma. Acta Haematol 123: 91-95, 2010.

13. Henríquez-Hernández LA, Navarro $\mathrm{P}$, Luzardo OP, et al: Polymorphisms of glutathione S-transferase $\mu$ and $\theta$, MDR1 and VEGF genes as risk factors of bladder cancer: a case-control study. Urol Oncol 30: 660-665, 2012.

14. Hofmann G, Langsenlehner U, Renner W, et al: Common single nucleotide polymorphisms in the vascular endothelial growth factor gene and colorectal cancer risk. J Cancer Res Clin Oncol 134: 591-595, 2008

15. Howell WM, Bateman AC, Turner SJ, Collins A and Theaker JM: Influence of vascular endothelial growth factor single nucleotide polymorphisms on tumour development in cutaneous malignant melanoma. Genes Immun 3: 229-232, 2002.

16. Hsiao PJ, Lu MY, Chiang FY, Shin SJ, Tai YD and Juo SH: Vascular endothelial growth factor gene polymorphisms in thyroid cancer. J Endocrinol 195: 265-270, 2007.

17. Ianni M, Porcellini E, Carbone I, et al: Genetic factors regulating inflammation and DNA methylation associated with prostate cancer. Prostate Cancer Prostatic Dis 16: 56-61, 2013.

18. Jacobs EJ, Feigelson HS, Bain EB, et al: Polymorphisms in the vascular endothelial growth factor gene and breast cancer in the Cancer Prevention Study II cohort. Breast Cancer Res 8: R22, 2006.

19. Jaiswal PK, Tripathi N, Shukla A and Mittal RD: Association of single nucleotide polymorphisms in vascular endothelial growth factor gene with bladder cancer risk. Med Oncol 30: 509, 2013.

20. Jang MJ, Jeon YJ, Kim JW, et al: Association of VEGF and KDR single nucleotide polymorphisms with colorectal cancer susceptibility in Koreans. Mol Carcinog 52 (Suppl 1): E60-E69, 2013.

21. Jin Q, Hemminki K, Enquist K, et al: Vascular endothelial growth factor polymorphisms in relation to breast cancer development and prognosis. Clin Cancer Res 11: 3647-3653, 2005.
22. Kämmerer PW, Koch FP, Schiegnitz E, et al: Associations between single-nucleotide polymorphisms of the VEGF gene and long-term prognosis of oral squamous cell carcinoma. J Oral Pathol Med 42: 374-381, 2013.

23. Ke Q, Liang J, Wang LN, et al: Potentially functional polymorphisms of the vascular endothelial growth factor gene and risk of gastric cancer. Mol Carcinog 47: 647-651, 2008.

24. Kim YH, Kim MA, Park IA, et al: VEGF polymorphisms in early cervical cancer susceptibility, angiogenesis, and survival. Gynecol Oncol 119: 232-236, 2010.

25. Li Y, Liang J, Liu X, et al: Correlation of polymorphisms of the vascular endothelial growth factor gene and the risk of lung cancer in an ethnic Han group of North China. Exp Ther Med 3: 673-676, 2012.

26. Li Y, Wang Y, Kang S, et al: Association of vascular endothelial growth factor gene polymorphisms with susceptibility to epithelial ovarian cancer. Int J Gynecol Cancer 20: 717-723, 2010.

27. Liang J, Yu X, Liu X, et al: Vascular endothelial growth factor polymorphisms and risk of lung cancer. Chin Ger J Clin Oncol 8: 269-272, 2009

28. Maltese P, Canestrari E, Ruzzo A, et al: VEGF gene polymorphisms and susceptibility to colorectal cancer disease in Italian population. Int J Colorectal Dis 24: 165-170, 2009.

29. Martinez-Fierro ML, Garza-Veloz I, Rojas-Martinez A, et al: Positive association between vascular endothelial growth factor (VEGF) -2578 C/A variant and prostate cancer. Cancer Biomark 13: 235-241, 2013.

30. Mishra K, Behari A, Kapoor VK, Khan MS, Prakash S and Agrawal S: Vascular endothelial growth factor single-nucleotide polymorphism in gallbladder cancer. J Gastroenterol Hepatol 28: 1678-1685, 2013

31. Nasr HB, Chahed K, Bouaouina N and Chouchane L: Functional vascular endothelial growth factor $-2578 \mathrm{C} / \mathrm{A}$ polymorphism in relation to nasopharyngeal carcinoma risk and tumor progression. Clin Chim Acta 395: 124-129, 2008.

32. Nikiteas NI, Tzanakis N, Theodoropoulos G, et al: Vascular endothelial growth factor and endoglin (CD-105) in gastric cancer. Gastric Cancer 10: 12-17, 2007.

33. Park HM, Hong SH, Kim JW, et al: Gender-specific association of the VEGF -2578C > A polymorphism in Korean patients with colon cancer. Anticancer Res 27: 2535-2539, 2007.

34. Pharoah PD, Tyrer J, Dunning AM, Easton DF and Ponder BA; SEARCH Investigators: Association between common variation in 120 candidate genes and breast cancer risk. PLoS Genet 3: e42, 2005.

35. Sáenz-López P, Vazquez F, Cozar JM, Carretero R, Garrido F and Ruiz-Cabello F: VEGF polymorphisms are not associated with an increased risk of developing renal cell carcinoma in Spanish population. Hum Immunol 74: 98-103, 2013.

36. Supic G, Jovic N, Zeljic K, Kozomara R and Magic Z: Association of VEGF-A genetic polymorphisms with cancer risk and survival in advanced-stage oral squamous cell carcinoma patients. Oral Oncol 48: 1171-1177, 2012.

37. VanCleave TT, Moore JH, Benford ML, et al: Interaction among variant vascular endothelial growth factor (VEGF) and its receptor in relation to prostate cancer risk. Prostate 70: 341-352, 2010.

38. Wang K, Liu L, Zhu ZM, Shao JH and Xin L: Five polymorphisms of vascular endothelial growth factor (VEGF) and risk of breast cancer: a meta-analysis involving 16,703 individuals. Cytokine 56: 167-173, 2011.

39. Wu LM, Xie HY, Zhou L, Yang Z, Zhang F and Zheng SS: A single nucleotide polymorphism in the vascular endothelial growth factor gene is associated with recurrence of hepatocellular carcinoma after transplantation. Arch Med Res 40: 565-570, 2009.

40. Zhang L, Zhang G, Wang P, Gong J, Cao Y and Tang L: Association of vascular endothelial growth factor $-2578 \mathrm{C} / \mathrm{A}$ gene polymorphism in Chinese patients with colon cancer. Genet Test Mol Biomarkers 15: 117-121, 2011.

41. Kim EJ, Jeong P, Quan C, et al: Genotypes of TNF-alpha, VEGF, hOGG1, GSTM1, and GSTT1: useful determinants for clinical outcome of bladder cancer. Urology 65: 70-75, 2005. 